Sharif University of Technology
Scientia Iranica
Transactions A: Civil Engineering
SCIENTIA $\quad \begin{aligned} & \text { http://scientiairanica.sharif.edu } \\ & \text { IRAN ICA }\end{aligned}$

\title{
Simulation of the force-displacement behavior of reinforced concrete beams under different degrees and locations of corrosion
}

\author{
M.A. Shayanfar ${ }^{\mathrm{a}}$, A. Hatami ${ }^{\mathrm{b}}$, M. Zabihi-Samani ${ }^{\mathrm{c}, *}$, B. Babakhani ${ }^{\mathrm{d}}$, and \\ A.R. Faroughi ${ }^{\mathrm{d}}$ \\ a. The Centre of Excellence for Fundamental Studies in Structural Engineering, Iran University of Science and Technology, \\ Narmak, Tehran, P.O. Box 16765-163, Iran. \\ b. School of Civil Engineering, Iran University of Science and Technology, Narmak, Tehran, P.O. Box 16765-163, Iran. \\ c. Department of Civil Engineering, Parand Branch, Islamic Azad University, Parand, Iran. \\ d. Department of Civil Engineering, East Tehran Branch, Islamic Azad University, Tehran, Iran.
}

Received 9 February 2020; received in revised form 28 April 2021; accepted 5 July 2021

\author{
KEYWORDS \\ Corrosion in \\ reinforced concrete \\ structures; \\ Bending capacity; \\ Finite element \\ analysis; \\ ABAQUS software; \\ $\mathrm{P}-\Delta$ diagram.
}

\begin{abstract}
Concerns about corrosion damage have been intensified due to the failure in marine structures and bridges. In this study, several simulations and tests have been accomplished to investigate the effect of corrosion on bending and shear capacities of reinforced concrete beams. By using ABAQUS software, this research is set to analyze the other effects of corrosion on reinforced beams. The accuracy of simulation results has been verified by existing experiment results. Several concrete beams with different degrees of corrosion are modeled in ABAQUS software. The results of simulation were compared with experimental results. Moreover, force-displacement diagrams are produced to investigate the corrosion effects more precisely. This study investigates effects of corrosion location, amount and intensity of corrosion, concrete compressive strength, and bar yielding stress on reinforced concrete beams strength. Furthermore, the effects of different locations and different corrosion degrees in steel rebar area and integration between steel and concrete are evaluated due to corrosion. Results demonstrate that corrosion effect on the loading capacity of beams in the tension region is greater than that in the compressive part. Furthermore, the corrosion around support regions is remarkable.
\end{abstract}

(C) 2022 Sharif University of Technology. All rights reserved.

\section{Introduction}

The durability of Reinforced Concrete (RC) structures is more suitable than other existing structural

*. Corresponding author.

E-mail addresses: shayanfar@iust.ac.ir (M.A. Shayanfar); Ali.hatami@yahoo.com (A.Hatami); mzabihi@iust.ac.ir (M. Zabihi-Samani); bahrouz@iau.ac.ir (B. Babakhani);

Faroughi@iauet.ac.ir (A.R. Faroughi)

doi: $10.24200 /$ sci.2021.55422.4214 materials. However, steel corrosion is possible in special environment conditions. In the past, most of related studies concentrated on concrete strength against sulfate attacks. In the present, the effects of durability related to steel corrosion are investigated, specifically in the case of marine structures and bridges $[1,2]$. Rebar corrosion is a progressive process that is accomplished by transition of iron ions from steel. Ions $\left(\mathrm{Fe}^{2+}\right)$ transition in electrochemical reaction is carried out in concrete pores. This solvation occurs in a limited volume of water solution of concrete pore 
around steel. Solved iron ions react with hydroxide ions $\left(\mathrm{OH}^{-}\right)$and oxygen molecules $\left(\mathrm{O}_{2}\right)$ that provide different solid productions [3]. The results of this process are reduction of steel weight and rebar area. These productions in pore spaces of concrete cause expansion pressure. This internal pressure causes environmental tension stresses around the steel rebar. Therefore, tension cracks and layer rupture occur in concrete cover along steel rebars. As a result, the compressive strength of concrete and adhesion between rebar and concrete are reduced [4,5]. Several researchers have demonstrated that corrosion commonly occurs in chloride and carbonate ambience [6,7]. Mostly, steel bars in $\mathrm{RC}$ are protected from corrosion due to protective layer of high alkalified concrete around bar. With the passage of time and based on two states of chloride ions or carbonation, alkalization of concrete reduces the probability of corrosion along with humidity and oxygen [8,9]. Furthermore, corrosion hits concrete structures in polluted cities. Due to acidic rainfall and penetration of carbon dioxide to concrete, uniform type carbonation is occurred $[10,11]$. Given its significance, rebar corrosion in concrete structures has been noticed and investigated by numerous investigations [12-14]. Further research has been accomplished to study the displacement-force diagram in shear concrete beam $[15,16]$. In other research, several samples with $0 \%$, $10 \%$, and $30 \%$ corrosion under the same experiments were provided and tested. Hassan et al. [17] provided the displacement-force diagrams for reinforced concrete beams under different degrees of corrosion [18]. Other studies have managed to illustrate the displacementforce behavior of columns under corrosion by Shayanfar et al. [19]. One of the solutions to deal with rebar corrosion is the use of composite rebars [20]. Due to the corrosive environmental conditions in marine and offshore structures, rebar corrosion is very high in these areas. Severe rebar corrosion can reduce the capacity of the structure. If this problem is not controlled, it can reduce the seismic capacity of these structures [21]. Further researches have been done to rehabilitate structures to reduce corrosion damage. The use of polymer and composite coatings is one of the solutions to deal with this problem [22-24]. Most studies have investigated experimental samples and this procedure is an expensive and long-term process that requires special facilities. The novelty of the current research lies in evaluating the characteristics of $\mathrm{RC}$ beams in corrosion with experimental and numerical investigations. Furthermore, the proposed model can determine the amount of tolerable corrosion in beam reduction capacity. Furthermore, effects of different locations and corrosion degrees are also considered. Variations of the cross-section of steel, mechanical characteristics of concrete and steel, and integration of steel and concrete are also investigated.

\section{The effects of rebar corrosion on $\mathrm{RC}$ structures}

The effects of corrosion on structural capacity used in Section 4 are introduced in this part.

\subsection{Bars area reduction}

One of the main effects of corrosion is the reduction of cross-section area in steel bars. several studies have proposed experimental equations to estimate crosssection area reduction of steel bars due to local corrosion $[25,26]$.

$$
A_{s(\mathrm{corr})}=\frac{\pi\left(D_{0}-n p(t)\right)}{4}
$$

where $A_{s \text { (corr) }}$ is the rebar area after corrosion, $D_{0}$ bar diameter before corrosion, $n$ one- or two-side corrosion attack, and $p(t)$ the corrosion depth. A number of researchers have proposed the same experimental equation to consider cross-section area reduction of steel bars due to global corrosion [27,28]. To simulate the percentage of difference in bar corrosion, it is modeled using parameter $\% x$. A new cross-section in ABAQUS software is expressed as follows:

$$
\begin{aligned}
\left(\frac{\pi\left(D_{0}^{2}\right)}{4} \times l\right) & \times \rho \times(\% x)=\left(\frac{\pi\left(D_{1}^{2}\right)}{4} \times l\right) \times \rho \rightarrow D_{1} \\
& =\sqrt{\% x} \times D_{0}
\end{aligned}
$$

In Eq. (2), $\rho$ is steel density, $x$ percentage of corrosion or weight loss percentage, and $D_{1}$ diameter of rebar after corrosion .

\subsection{The reduction of bar tensile strength}

Another important effect of corrosion is the reduction of steel bars yielding stress. Several researchers have presented a formula between steel bars yielding strain and corrosion degree. This formula utilizes concrete cover and rebar dimension [29]. Furthermore, other experimental results demonstrate $30 \%$ and $50 \%$ rates of reduction in maximum strain. This corrosion result is caused by $15 \%$ and $28 \%$ decreases in the crosssection area of bar [30,31]. Further studies have pointed out that the yielding and ultimate stress of steel are reduced slightly following corrosion increment [32,33]. Based on the experimental results, the modified yielding stress of steel bars can be expressed as follows:

$$
f_{y(\mathrm{corr})}=\left(1-0.005 \frac{A_{s(\mathrm{cor} r)}}{A_{0}}\right) f_{y 0},
$$

where $f_{y(\text { corr })}$ is the modified steel yielding stress after corrosion, $A_{s(\text { corr })}$ cross-sectional area of bar after corrosion, $A_{0}$ cross-sectional area of bar before corrosion, and $f_{y 0}$ basic steel yielding stress before corrosion. 


\subsection{Reduction strength between concrete and steel}

Most of conducted studies were carried out on the displacement-force diagram of RC beams under corrosion with experimental methods. The complex nature of corrosion phenomenon and involvement of numerous parameters including the cross-sectional area of bar, change in integration of concrete and steel, and effect on concrete strength should be considered. These parameters cannot be simply investigated through experimental tests [33]. Simulation results are also explored to demonstrate the corrosion effects with approximate equations $[34,35]$. Shayanfar and Safiey completed a simpler equation as an efficient model for a strain-pliable region. The formula can consider the reduction of concrete cohesion strength and predict the occurrence of cracks due to corrosion [36]. According to previous studies, tension stiffness curve is composed of two separated states, called final crack state. Therefore, the uniaxial tension strain-stress curve of the RC element is divided into three states. Effect of crack width and depth of corrosion are investigated through finite element simulation [37].

\subsection{Concrete strength reduction affected by corrosion crack}

Eq. (4) was used for simulating concrete treatment in pressure. By increasing the rust of steel in corrosion reaction (iron oxide), radial compressive force was created all over bar areas. This process causes tension stresses in concrete around bar. In the case of lowand medium-level corrosion, cracks and delamination occurred. The accuracy of Eq. (4) was proved through several experiments [38]:

$$
\lambda=2.288 C_{w}-1.733,
$$

where $C_{w}$ is the corrosion level and is the percentage of compressive strength reduction. The effects of severe corrosion could waste all concrete cover (spalling). In this study, these effects are ignored.

\section{Corrosion modeling in software}

For validation of the models in the study, the results obtained from ABAQUS software analysis for the RC beam have been compared with previous laboratory results [20]. To consider the effects of bar corrosion, the parameters described in Section 2 were utilized. The prediction of the displacement-force curve for a RC beam was made under corrosion in different conditions of location and intensity. At last, results were compared with each other.

\subsection{Modeling of benchmark beam in $A B A Q U S$ software}

A benchmark beam was utilized for validating the simulation and obtaining a displacement-force curve for RC beams. Figure 1 presents the characteristics of ABAQUS model. Solid element (C3D20) has been used for modeling concrete and rebar in finite element modeling. Moreover, the interaction between rebar and concrete is defined as an embedded region. General specifications of materials are given in Table 1. A $\mathrm{RC}$ structure is a composite structure made up of two materials with different characteristics. In general, the external load has already been applied to concrete surface. By using bonding, the reinforcing bars receive a part of their load only from the surrounding concrete. "Bond stress" is the name assigned to the shear stress at the bar-concrete interface. The stress of steel bar has been modified by transferring load between the bar and the surrounding concrete. A composite beam is formed from two materials, where the bonding is efficiently developed. In composite structures, bonding between

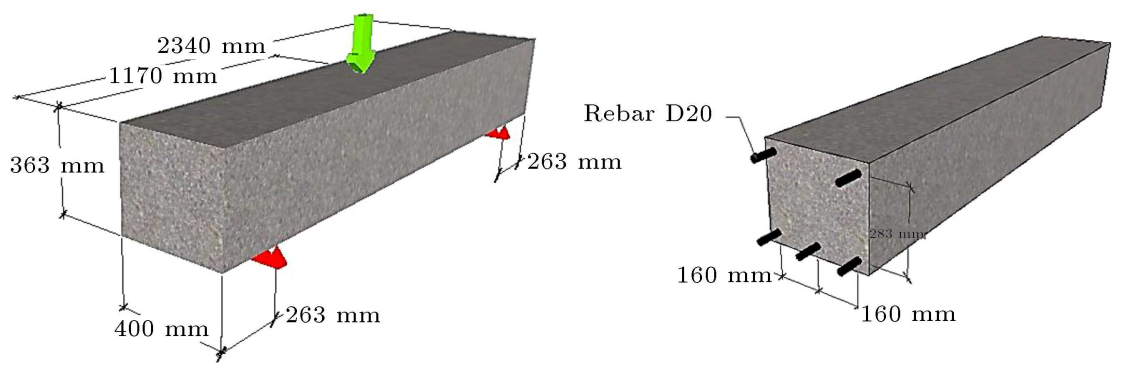

Figure 1. Reinforced concrete characteristics of the case study toward modeling method validation.

Table 1. Specifications of the material.

\begin{tabular}{cccc}
\hline Material & Specific weight $\left(\mathbf{k g} / \mathbf{m}^{\mathbf{3}}\right)$ & Young's modulus $\left(\mathrm{N} / \mathbf{m}^{\mathbf{2}}\right)$ & Poisson's ratio \\
\hline Rebar & 7750 & $2.5 \mathrm{E} 11$ & 0.3 \\
Concrete & 2200 & $2.05 \mathrm{E} 10$ & 0.2 \\
\hline
\end{tabular}




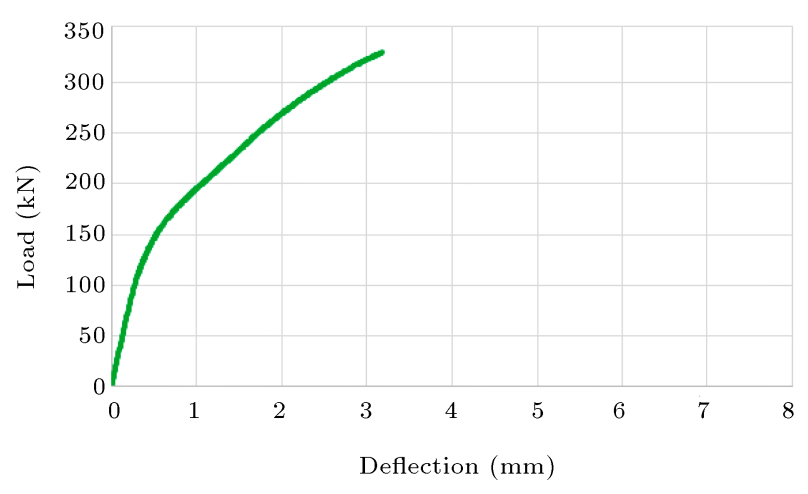

Figure 2. Displacement-force diagram of the beam in software in Figure 1.

different components of RC plays a primary role. These complex phenomena led engineers in the past to rely heavily on experimental formulas for designing concrete structures. These equations have been derived from numerous experiments. For these reasons, the integration of bonds has been done significantly in recent works $[39,40]$. The properties of this interaction depend on several factors: friction, mechanical interaction, chemical adhesion, and different alternative representations of reinforcement. Moreover, smeared, embedded and discrete reinforcement models had several differences. The first one is rarely used and therefore, depends on the nature of the used structure. The discrete and embedded representations are formulated and introduced in the developed program [41-43].

This beam is modeled in software and all parameters are obtained based on the defined equations in Section 2. For the case study, the beam shown in Figure 2 was utilized.

\subsection{Simulation results validation}

The simulation results were validated in comparison with displacement-force curve of experimental results. Figure 3 demonstrates that simulation and experimental results were in appropriate compliance. Therefore, it can be concluded that simulation process is reliable and provides similar results to experiments.

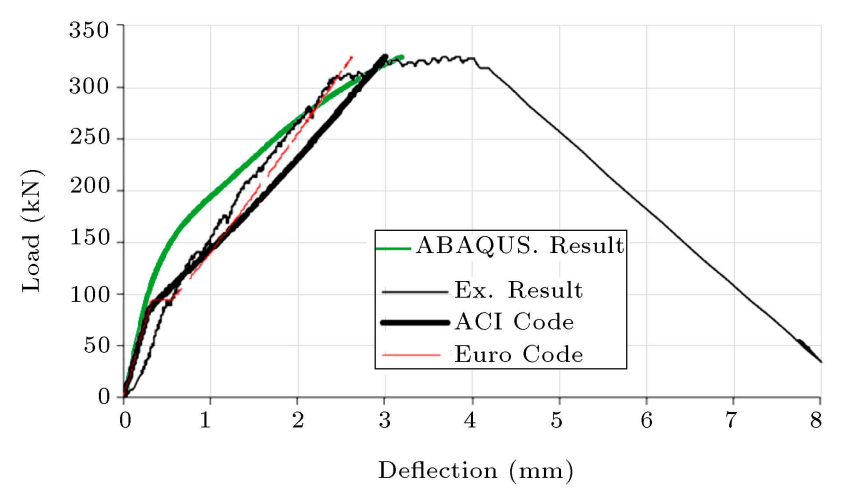

Figure 3. Modeling results comparison of Example 1 and software model (ABAQUS).

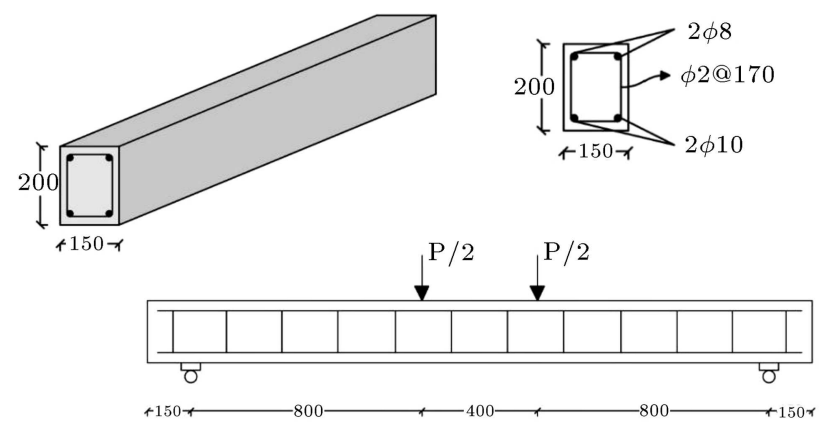

Figure 4. Case study model characteristics for studying different corrosion effects (dimensions are in $\mathrm{mm}$ ).

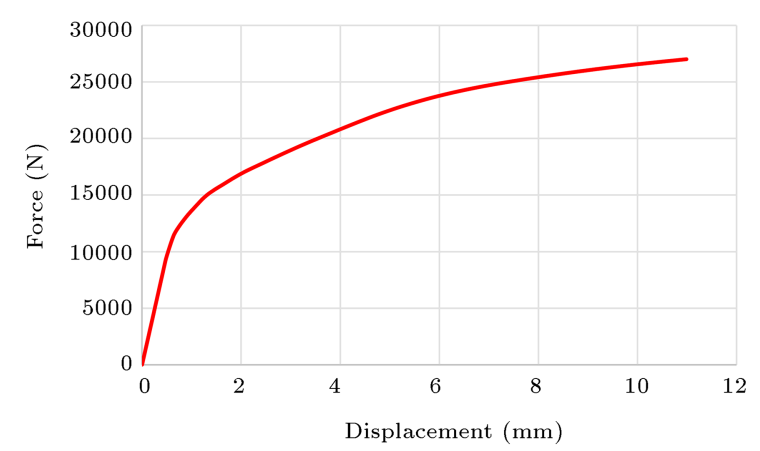

Figure 5. Displacement-force chart of the beam in Figure 6 (before corrosion).

\section{Different corrosion effects on displacement-force curve of reinforced concrete beam}

Several simulation models were investigated to predict different corrosion effects on displacement-force curve of RC beams. For this purpose, a RC beam was studied. The characteristics of beam are shown in Figure 4. Before taking any action for corrosion simulation, the beam was modeled in natural conditions. The results of $\mathrm{RC}$ beam without corrosion are presented in Figure 5 . It can be seen that the beam demonstrated $26500 \mathrm{~N}$ axial force strength before destruction.

\section{1. $10 \%$ corrosion effect in whole RC beam}

$\mathrm{RC}$ beam with $10 \%$ corrosion is investigated in this section. Based on Eq. (3), the remaining diameter of steel rebars was defined after corrosion. The modified section area can be simulated as follows:

Up bars (compressive bars) with 8-millimeter dimension:

$$
D_{1}=\sqrt{0.9} \times D_{0} \rightarrow D_{1}=\sqrt{0.9} \times(8)=7.59 \mathrm{~mm} .
$$

Bellow bars (tension bars) with 10-millimeter dimension:

$$
D_{1}=\sqrt{0.9} \times D_{0} \rightarrow D_{1}=\sqrt{0.9} \times(10)=9.49 \mathrm{~mm} .
$$

Stirrups (cross bars) with 6-millimeter dimension: 


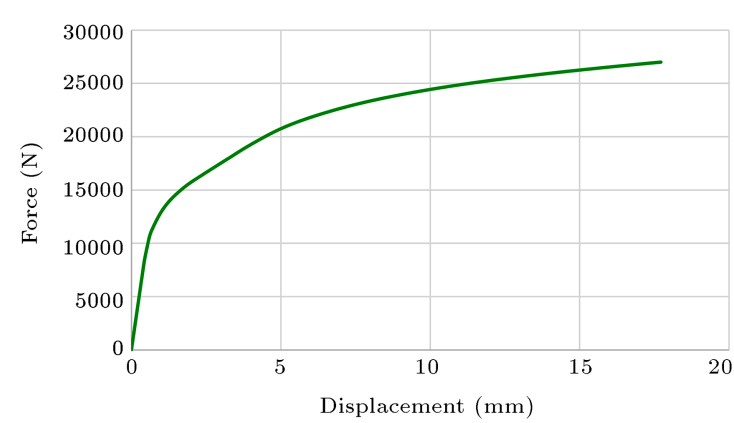

Figure 6. Beam displacement-force chart under $10 \%$ corrosion (model under $26500 \mathrm{~N}$ load in 1 second period).

$$
D_{1}=\sqrt{0.9} \times D_{0} \rightarrow D_{1}=\sqrt{0.9} \times(6)=5.69 \mathrm{~mm} .
$$

Based on the definitions presented in Section 2, other parameters such as concrete and steel strength reduction were considered. Figure 6 demonstrates the displacement-force curve of beam under $10 \%$ corrosion. The beam can withstand up to $26500 \mathrm{~N}$ axial force loads in 1 second. The $17.5 \mathrm{~mm}$ displacement occurred. More simulations for different corrosions percentage were performed.

\section{2. $30 \%$ corrosion effect in the whole $R C$ beam}

Figure 7 shows the displacement-force curve of the case study, as shown in Figure 4. In this beam, 30\% corrosion in rebars is utilized. The dimension of steel rebar after corrosion is organized as follows:

- Up bars (compressive armatures) with a 8millimeter dimension were converted into $D=$ $\sqrt{0.7} \times(8)=6.69 \mathrm{~mm}$ dimension;

- Bellow bars (tension rebar) with a 10-millimeter dimension were converted into $\sqrt{0.7} \times(10)=8.37 \mathrm{~mm}$ dimension;

- Stir-ups (cross bars) with a 6-millimeter dimension were converted into $\sqrt{0.7} \times(6)=5.02 \mathrm{~mm}$ dimension.

According to Figure 8, the displacement-force curve of the same beam was compared under different degrees

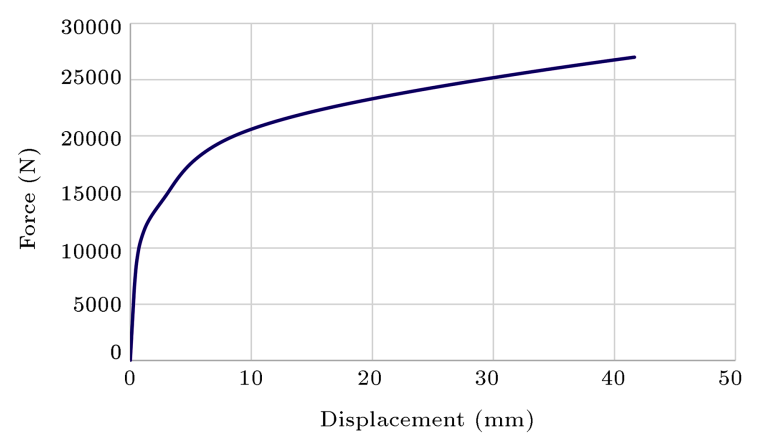

Figure 7. Beam displacement-force chart under $30 \%$ corrosion (model under $26500 \mathrm{~N}$ load in 1 second period).

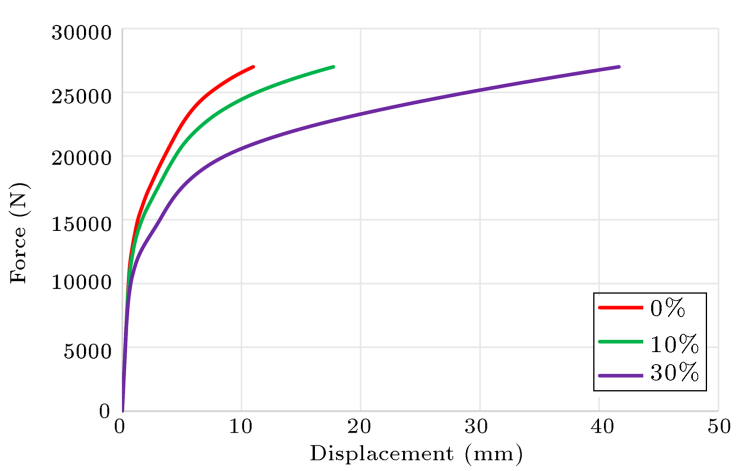

Figure 8. Comparison of beam behavior under different corrosion degrees (models under $26500 \mathrm{~N}$ load in 1 second period).

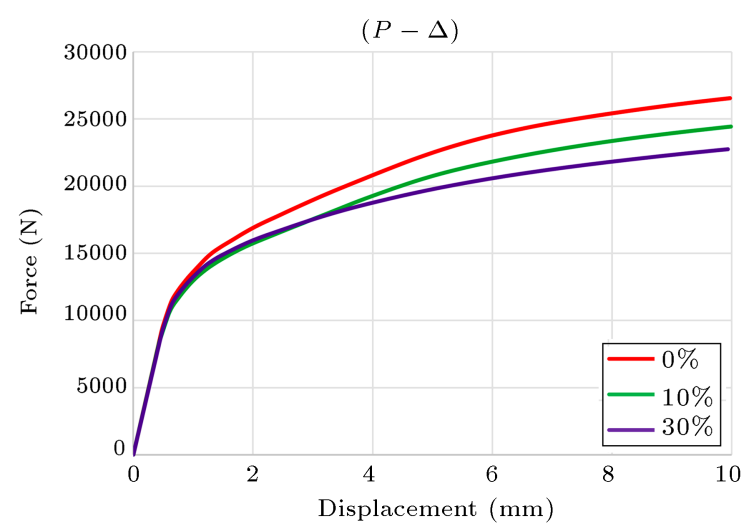

Figure 9. Beam behavior comparison of the example under different corrosions percentages in Figure 3.

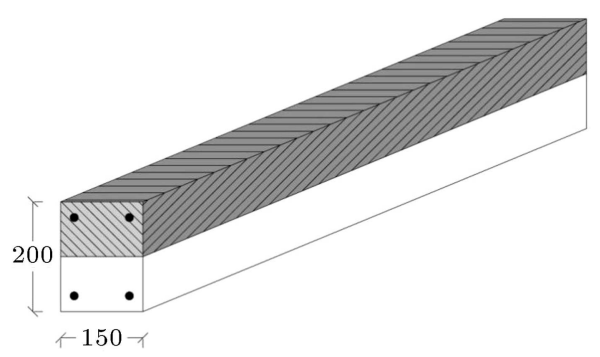

Figure 10. Case study of concrete beam under corrosion effect in the compressive section of region.

of corrosion. After 1 second from start of loading, the applied load reaches to $26500 \mathrm{~N}$ in $0 \%, 10 \%$, and $30 \%$ corroded beams. For the same time and force, the displacement of $30 \%$ corroded beam significantly increased in comparison with others.

Beam deflection criteria are $\frac{L}{360}=5.5 \mathrm{~mm}$ and $\frac{L}{240}=8.3 \mathrm{~mm}$; extracted charts are drawn from the displacement-force curves in Figures 9 and 10 . The results are compared as shown in Table 2 .

\subsection{The effects of corrosion in different locations with the same degree of corrosion}

In the case of the one-degree corrosion of a very $\mathrm{RC}$ 
Table 2. Behavior comparison of a constant model under different corrosion percentages.

\begin{tabular}{cccc}
\hline Displacement amount & $\mathbf{5} \mathbf{~ m m}$ & $\mathbf{1 0} \mathbf{~ m m}$ & $\mathbf{1 5} \mathbf{~ m m}$ \\
\hline $0 \%$ corrosion & $22500(\mathrm{~N})$ & $26500(\mathrm{~N})$ & - \\
$10 \%$ corrosion & $20700(\mathrm{~N})$ & $24600(\mathrm{~N})$ & $26258(\mathrm{~N})$ \\
$30 \%$ corrosion & $17500(\mathrm{~N})$ & $20500(\mathrm{~N})$ & $24470(\mathrm{~N})$ \\
\hline
\end{tabular}

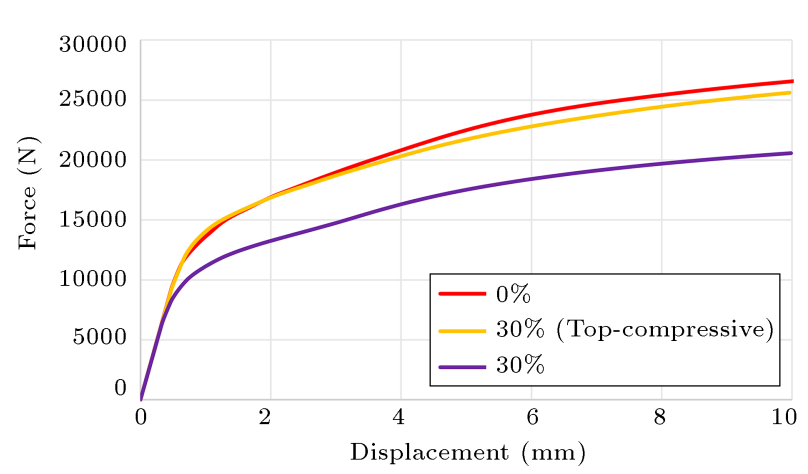

Figure 11. The reinforced concrete beam behavior under corrosion in compressive part and with no corrosion beam and beam under $30 \%$ corrosion along its length in comparison.

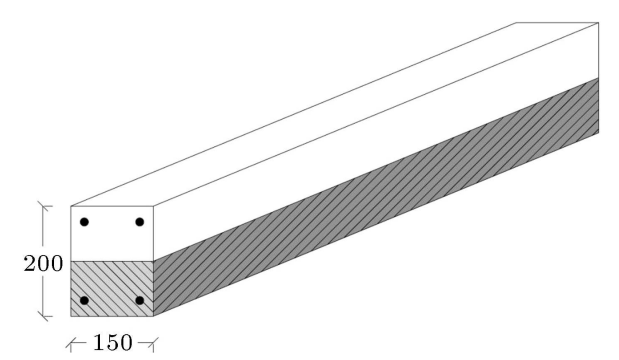

Figure 12. The case study of concrete beam under corrosion effect in the tension section of region.

beam given in Figure 4, a displacement-force chart under $30 \%$ corrosion was drawn in different locations. Figure 11 shows the RC beam behavior at different corrosion levels: $30 \%$ corrosion in the compressive part, $30 \%$ in all of sections, and no corrosion. Figures 9 and 10 demonstrate that $10 \%$ of the global corrosion effect on beam capacity reduction is greater than $30 \%$ corrosion in the compressive region. Figure 12 shows $30 \%$ corrosion effect in the following part (tension) in comparison with no corrosion beam and $30 \%$ corrosion in all parts of the beam. From the comparison of Figures 11 and 13, it is concluded that corrosion is more effective in tension part than that in compressive part. For $10 \mathrm{~mm}$ displacement in the middle span, $26500 \mathrm{~N}$ force is required in the case of no corrosion beam. The same displacement occurs for $30 \%$ corrosion beam with $20500 \mathrm{~N}$ force. The results show that due to $30 \%$ corrosion, the beam had a $20 \%$ decrease in resistance. The same displacement could be seen with $30 \%$ corrosion in compressive and tension areas by $25500 \mathrm{~N}$ and $22800 \mathrm{~N}$ force.

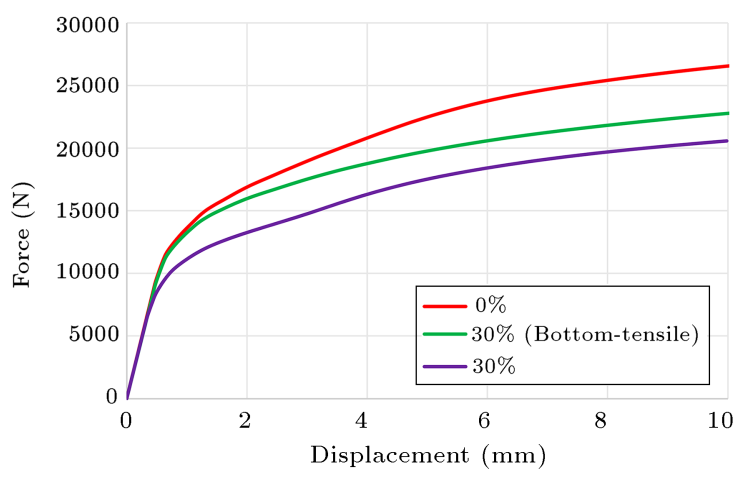

Figure 13. The behavior under corrosion in the beam tension part and its comparison with the start and end of beam with $30 \%$ corrosion.

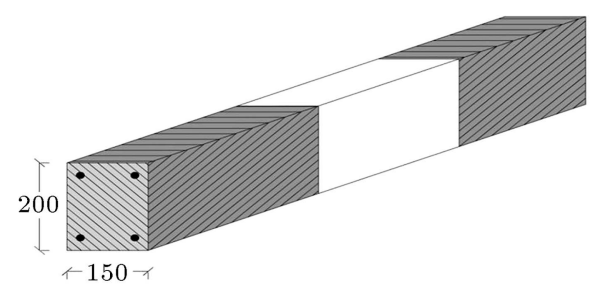

Figure 14. The concrete beam of the case study under corrosion effect of stirrups around supports region.

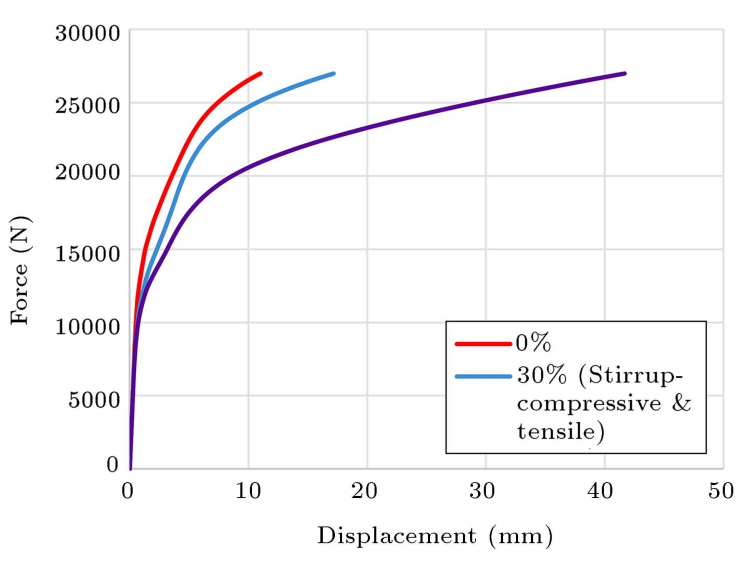

Figure 15. Reinforced concrete beam behavior under corrosion of stirrups around support with no corrosion beam and beam under 30\% corrosion along its length (models under $26500 \mathrm{~N}$ load in 1 second period).

Figures 14 and 15 illustrate the displacementforce curve for $30 \%$ corrosion in the support part in comparison with non-corrosion beam and beam under $30 \%$ total corrosion. The longitudinal rebars are not affected by corrosion and stirrups are affected. 
Table 3. The force amount and reinforced concrete beam capacity reduction percentage under $30 \%$ corrosion in different regions.

\begin{tabular}{lcccccc}
\hline & & {$[1]$} & {$[2]$} & {$[3]$} & {$[4]$} & {$[5]$} \\
\hline \multirow{2}{*}{$5.55 \mathrm{~mm}$} & Force (N) & 23,228 & 22,320 & 20,272 & 21,531 & 18,058 \\
& Capacity reduction & - & $3.9 \%$ & $12.7 \%$ & $7.3 \%$ & $22.2 \%$ \\
\multirow{2}{*}{$8.33 \mathrm{~mm}$} & Force (N) & 25,628 & 24,662 & 21,998 & 23,902 & 19,868 \\
& Capacity reduction & - & $3.7 \%$ & $14.2 \%$ & $6.7 \%$ & $22.5 \%$ \\
\hline
\end{tabular}

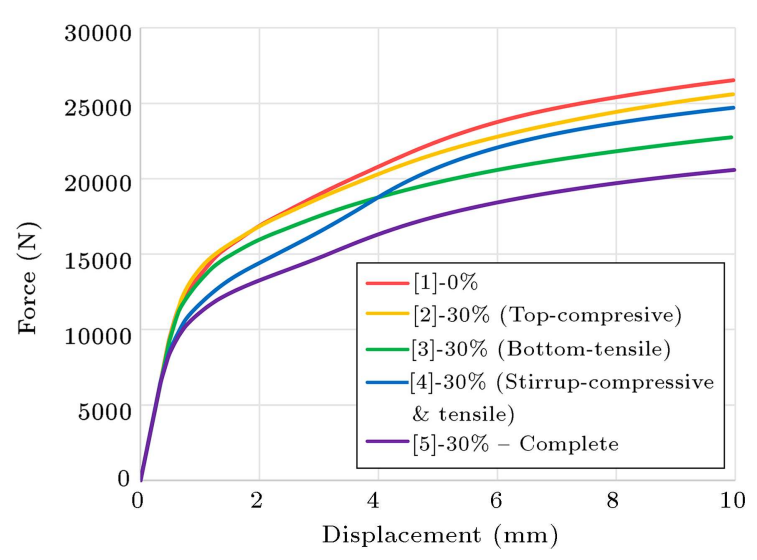

Figure 16. Reinforced concrete beam behavior under $30 \%$ corrosion in different regions.

The results demonstrate that tension capacities have been reduced. Furthermore, compressive properties, concrete, and integration of steel and concrete are affected by corrosion. Finally, a comparison of the displacement-force curve under $30 \%$ corrosion is drawn in different locations in Figure 16. To make a better comparison, possible corrosion cases are shown in Table 3. The maximum force value and beam capacity reduction amount were shown in each case. The results were illustrated for two specified criteria based on span length $(5.55 \mathrm{~mm}, 8.33 \mathrm{~mm})$.

\section{Conclusion}

The corrosion location and amount in any region and special environmental conditions differed. In this study, the displacement-force curve of a Reinforced Concrete (RC) beam was studied under different corrosion effects and locations. Based on the conducted analysis, the following results were obtained:

- Corrosion effects on global beam behavior in the whole length and around and external environments of beam were greater than corrosion effect in the tension or compressive parts and stirrups;

- Generally, corrosion effect on the loading capacity of beams in the tension region was greater than corrosion in the compressive part. Furthermore, the corrosion around support regions was remarkable and corrosion effect in the compressive region was lower than that in other two states;

- In $10 \%$ and $30 \%$ of the whole corrosion cases, the force capacity reductions were calculated as $7 \%$ and $14 \%$, respectively;

- 5.5- and 8.3-millimeter displacements of the middle span were utilized as deflection control criteria in beams. The capacity reduction values were calculated as $22 \%, 13 \%, 7 \%$, and $4 \%$ for the whole corrosion, tension region corrosion, stirrups corrosion around support, and compressive region cases, respectively.

Results demonstrated that corrosion effect on loading capacity of beams in the tension region was greater than that in the compressive part. Furthermore, the corrosion around support regions is remarkable.

\section{References}

1. Val, D.V. and Chernin, L. "Serviceability reliability of reinforced concrete beams with corroded reinforcement", Journal of Structural Engineering, 135(8), pp. 896-905 (2009).

2. Zabihi Samani, M., Mokhtari, S.P., and Raji, F. "Effects of fly ash on mechanical properties of concrete", Journal of Applied Engineering Sciences, 8, pp. 35-40 (2018).

3. Ghanooni-Bagha, M., Shayanfar, M.A., Reza-Zadeh, O., et al. "The effect of materials on the reliability of reinforced concrete beams in normal and intense corrosions", Eksploatacja i Niezawodnosc-Maintenance and Reliability, 19(3), pp. 393-402 (2017).

4. Ghanooni-Bagha, M., Shayanfar, M.A., ShirzadiJavid, A., et al. "Corrosion-induced reduction in compressive strength of self-compacting concretes containing mineral admixtures", Construction and Building Materials, 113(15), pp. 221-228 (2016).

5. Shayanfar, M.A., Barkhordari, M.A., and GhanooniBagha, M. "Estimation of corrosion occurrence in RC structure using reliability based PSO optimization", Periodica Polytechnica Civil Engineering, 59(4), pp. 531-542 (2015). 
6. Bertolini, B.E., Pedeferri, P., Redaelli, E., et al. "Corrosion of Steel in Concrete", Prevention, Diagnosis, Repair. WILEY-VCH Verlag GmbH and Co. KGaA, Weinheim (2014).

7. Amini, F. and ZabihiSamani, M. "A wavelet-based adaptive pole assignment method for structural control", Computer-Aided Civil and Infrastructure Engineering, 29(6), pp. 464-477 (2014).

8. Peter, M.A., Muntean, A., Meier, A., et al. "Competition of several carbonation reactions in concrete: A parametric study", Cement and Concrete Research, 38(12), pp. 1385-1393 (2008).

9. Honarvar, H., Shayanfar, M.A., Babakhani, B., et al. "Numerical analysis of steel-concrete composite beam with blind bolt under simultaneous flexural and torsional loading", Civil Engineering Infrastructures Journal, 53(2), pp. 379-393 (2020).

10. Dekoster, M., Buyle-Bodin, F., Maurel, O., et al. "Modelling of the flexural behaviour of RC beams subjected to localised and uniform corrosion", Engineering Structures, 25(10), pp. 1333-1341 (2003).

11. Sabbagh-Yazdi, S.R., Farhoud, A., and Zabihi-Samani, M. "Transient Galerkin finite volume solution of dynamic stress intensity factors", Asian Journal of Civil Engineering, 20(3), pp. 371-381 (2019).

12. Guzmán, S., Gálvez, J.C., and Sancho, J.M. "Cover cracking of reinforced concrete due to rebar corrosion induced by chloride penetration", Cement and Concrete Research, 41(8), pp. 893-902 (2011).

13. Malumbela, G., Moyo, P., and Alexander, M. "Influence of corrosion crack patterns on the rate of crack widening of RC beams", Construction and Building Materials, 25(5), pp. 2540-2553 (2011).

14. Younsi, A., Turcry, P., Roziére, E., et al. "Performance-based design and carbonation of concrete with high fly ash content", Cement and Concrete Composites, 33(10), pp. 993-1000 (2011).

15. Toongoenthong, K. and Maekawa, K. "Multimechanical approach to structural performance assessment of corroded RC members in shear", Journal of Advanced Concrete Technology, 3(1), pp. 107-122 (2005).

16. Zabihi-Samani, M., Shayanfar, M., Safiey, A., et al. "Simulation of the behavior of corrosion damaged reinforced concrete beams with/without CFRP retrofit", Civil Engineering Journal, 4(5), pp. 958-970 (2018).

17. DiCarlo, F., Meda, A., and Rinaldi, Z. "Numerical evaluation of the corrosion influence on the cyclic behaviour of RC columns", Engineering Structures, 153(15), pp. 264-278 (2017).

18. Hassan, A.A.A., Hossain, K.M.A., and Lachemi, M. "Structural assessment of corroded self-consolidating concrete beams", Engineering Structures, 32(3), pp. 874-885 (2010).

19. Shayanfar, M., Bigonah, M., Sobhani, D., et al. "The effectiveness investigation of new retrofitting techniques for RC frame against progressive collapse", Civil Engineering Journal, 4(9), pp. 2132-2142 (2018).
20. Omrani, M.H., Dehestani, M., and Yousefpour, H. "Flexural behavior of lightweight concrete beams reinforced with GFRP bars and prestressed with steel strands", Structural Concrete, 22, pp. 69-80 (2021).

21. Qin, F., Liu, T., Yang, F., et al. "Simulation on aseismic behaviors of reinforced concrete corroded in marine environment", Journal of Coastal Research, 94(1), pp. 21-25 (2019).

22. Afshin, H., Shirazi Mohammad, R.N., and Abedi, K. "Experimental and numerical study about seismic retrofitting of corrosion-damaged reinforced concrete columns of bridge using combination of FRP wrapping and steel profiles", Steel and Composite Structures, 30(3), pp. 231-251 (2019).

23. Bareiro, W.G., AndradeSilva, F., and Sotelino, E.D. "Thermo-mechanical behavior of stainless-steel fiber reinforced refractory concrete: Experimental and numerical analysis", Construction and Building Materials, 240(20) p. 117881 (2020).

24. Yu, F., Song, Z., Mansouri, I., et al. "Experimental study and finite element analysis of PVC-CFRP confined concrete column-Ring beam joint subjected to eccentric compression", Construction and Building Materials, 254, p. 119081 (2020).

25. Berto, L., Simioni, P., and Saetta, A. "Numerical modelling of bond behaviour in RC structures affected by reinforcement corrosion", Engineering Structures, 30(5), pp. 1375-1385 (2008).

26. Zabihi-Samani, M. and Ghanooni-Bagha, M. "Optimal semi-active structural control with a wavelet-based cuckoo-search fuzzy logic controller", Iranian Journal of Science and Technology, Transactions of Civil Engineering, 43(4), pp. 619-634 (2018).

27. Alipour, A., Shafei, B., and Shinozuka, M. "Life cycle cost analysis of reinforced concrete highway bridges in chloride contaminated environments", In Structures Congress, pp. 644-653 (2010).

28. Val, D.V. and Melchers, R.E. "Reliability of deteriorating RC slab bridges", Journal of Structural Engineering, 123(12), pp. 1638-1644 (1997).

29. Shayanfar, M.A., Ghalehnovi, M., and Safiey, A. "Corrosion effects on tension stiffening behavior of reinforced concrete", Computers and Concrete, 4(5), pp. 403-424 (2007).

30. Zabihi-Samani, M. "Design of optimal slit steel damper under cyclic loading for special moment frame by cuckoo search", International Journal of Steel Structures, 19(4), pp. 1260-1271 (2019).

31. Du, Y.G., Clark, L.A., and Chan, A.H.C. "Residual capacity of corroded reinforcing bars", Magazine of Concrete Research, 57(3), pp. 135-147 (2005).

32. Apostolopoulos, C.A., Demis, S., and Papadakis, V.G. "Chloride-induced corrosion of steel reinforcementMechanical performance and pit depth analysis", Con- 
struction and Building Materials, 38, pp. 139-146 (2013).

33. Wei-liang, J. and Yu-xi, Z. "Effect of corrosion on bond behavior and bending strength of reinforced concrete beams", Journal of Zhejiang University-SCIENCE A., 2(3), pp. 298-308 (2001).

34. Bertolini, L. "Steel corrosion and service life of reinforced concrete structures", Structure and Infrastructure Engineering, 4(2), pp. 123-137 (2008).

35. Al-Sulaimani, G.J., Kaleemullah, M., Basunbul, I.A., et al. "Influence of corrosion and cracking on bond behavior and strength of reinforced concrete members", Aci Structural Journal, 87, pp. 220-231 (1990).

36. Shayanfar, M. and Safiey, A. "A new approach for nonlinear finite element analysis of reinforced concrete structures with corroded reinforcements", Computers and Concrete, 5(2), pp. 155-174 (2008).

37. Ghanooni-bagha, M., Shayanfar, M.A., and Farnia, M.H. "Cracking effects on chloride diffusion and corrosion initiation in RC structures via finite element simulation", Scientia Iranica, 27(5), pp. 2301-2315 (2020).

38. Shayanfar, M.A., Barkhordari, M.A., and GhanooniBagha, M. "Effect of longitudinal rebar corrosion on the compressive strength reduction of concrete in reinforced concrete structure", Advances in Structural Engineering, 19(6), pp. 897-907 (2016).

39. Kwak, H.G. and Kim, S.P. "Bond-slip behavior under monotonic uniaxial loads", Engineering Structures, 23(3), pp. 298-309 (2001).

40. Khalfallah, S. "Tension stiffening bond modelling of cracked flexural reinforced concrete beams", Journal of Civil Engineering and Management, 14(2), pp. 131137 (2008).

41. Khalfallah, S. and Ouchenane, M. "A numerical simulation of bond for pull out tests: The direct problem", Asian Journal of Civil Engineering, 8(5), pp. 491-505 (2007).

42. Bigonah, M., Soltani, H., Zabihi-Samani, M., et al. "Performance evaluation on effects of all types of infill against the progressive collapse of reinforced concrete frames", Asian Journal of Civil Engineering, 21, pp. 395-409 (2020).

43. Rezaei, M., Ranjbar Karkanaki, A., and Zabihi Samani, M. "Experimental investigation of deep beams containing high-performance fiber-reinforced cementitious composite", Iranian Journal of Science and Technology, Transactions of Civil Engineering, 46(1), pp. 55-65 (2021). https://doi.org/10.1007/s40996-02100653-4

\section{Biographies}

MohsenAli Shayanfar received $\mathrm{PhD}$ degree at McGill University in 1995. Now, he is an Associate
Professor at Iran University of Science and Technology, Tehran, Iran. His research interests include nonlinear finite element method, reliability analysis, durability prediction of concrete structure, seismic rehabilitation, optimal structural control, wavelet analysis and health monitoring, construction management, and meta-heuristic.

Ali Hatami received MSc degree of Civil/Structural Engineering at Iran University of Science and Technology in 2016. His research orientation is towards modeling the corrosion phenomenon and its effects on structures. His research interests include nonlinear finite element method, corrosion, reliability analysis, and durability prediction of concrete structure.

Masoud Zabihi-Samani is an Assistant Professor in the field of Structural Engineering. He received his $\mathrm{PhD}$ degree from Iran University of Science and Technology in 2014. He is a Professor at the Civil Engineering Department at Parand Branch of Islamic Azad University where he taught several graduate and undergraduate courses, supervised $4 \mathrm{PhDs}$, and more than 40 master students. His areas of research include vibration control of structural systems, time endurance method, active and semi-active control, system identification, wavelet and curvelet analyses, and corrosion of concrete structures, in which he has published more than 60 peer-reviewed journal and conference papers nationally and internationally.

Behrouz Babakhani received $\mathrm{PhD}$ degree at ARAK branch of Islamic Azad University in 2018. His research orientation is towards modeling the corrosion phenomenon and its effects on structures. On this basis, regular programs have been set up in two areas of laboratory and theoretical research. One of the lowcost and widely used methods for investigating the effects of corrosion is finite element modeling. His research interests include corrosion, reliability analysis, and durability prediction of concrete structure.

Ali-Reza Faroughi is an Assistant Professor in the field of Structural Engineering. He received his $\mathrm{PhD}$ degree from Science and Research Branch of Islamic Azad University in 2016. He is a Professor and a Faculty member of Civil Engineering Department at Islamic Azad University, East Tehran Branch where he taught several graduate and undergraduate courses and supervised more than 30 master students. Furthermore, he is a member of working Group on the 5th edition of 2800 Standard Spectrum and Iranian Engineering Software Committee (IESC). His research interests include seismic design of structures, rehabilitation, and risk analysis of structure. 